\author{
Marquette University \\ e-Publications@Marquette
}

7-2011

\title{
Children's Perceptions of Intimate Partner Violence: Causes, Consequences, and Coping
}

Renee L. DeBoard-Lucas

Marquette University (graduate student)

John H. Grych

Marquette University, john.grych@marquette.edu

Follow this and additional works at: https://epublications.marquette.edu/psych_fac

Part of the Psychology Commons

\section{Recommended Citation}

DeBoard-Lucas, Renee L. and Grych, John H., "Children's Perceptions of Intimate Partner Violence: Causes, Consequences, and Coping" (2011). Psychology Faculty Research and Publications. 70.

https://epublications.marquette.edu/psych_fac/70 
Marquette University

\title{
e-Publications@Marquette
}

\section{Psychology Faculty Research and Publications/College of Arts and Science}

This paper is NOT THE PUBLISHED VERSION; but the author's final, peer-reviewed manuscript.

The published version may be accessed by following the link in the citation below.

Journal of Family Violence, Vol. 26, No. 5 (July, 2011): 343-354. DOI. This article is (C Springer and permission has been granted for this version to appear in e-Publications@Marquette. Springer does not grant permission for this article to be further copied/distributed or hosted elsewhere without the express permission from Springer.

\section{Children's Perceptions of Intimate Partner Violence: Causes, Consequences, and Coping}

\section{Renee L. DeBoard-Lucas}

Department of Psychology, Marquette University, Milwaukee, WI

John H. Grych

Department of Psychology, Marquette University, Milwaukee, WI

\begin{abstract}
Children's appraisals of conflictual and aggressive parental interactions mediate their effect on children's adjustment. Previous studies have relied almost exclusively on self-report questionnaires to assess appraisals; consequently we know little about perceptions that occur naturally when children witness interparental aggression. This study employed a semi-structured interview to assess the thoughts and feelings of 34 children (ages 7-12) whose mothers were receiving services at domestic violence agencies, and mothers reported on interparental aggression that took place in the home. Children's thoughts centered on consequences and efforts to understand why fights occurred. They generally viewed their mother's partner as responsible for violence, though a significant number viewed both parents as playing a role. Sadness and anger were more common than anxiety, and children often
\end{abstract}


attempted to stop or withdraw from fights or both. When asked why family violence occurs, most focused on perpetrators' lack of control of anger or personal characteristics, but approximately onethird viewed victims as provoking aggression. These findings support the idea that children actively attempt to understand the causes and consequences of interparental violence and suggest that their perceptions and interpretations are important for understanding the development of beliefs regarding the use of violence in close relationships.

\section{Keywords}

Perceptions; Intimate Partner Violence; Children; Semi-structured interviews

Intimate partner violence is a pervasive problem that affects the lives of millions of children. Approximately 15.5 million American children are exposed to at least one act of interparental violence every year, and seven million children live in households characterized by severe domestic violence (McDonald et al. 2006), which may include one parent beating or burning the other, threatening to use or using a knife or gun on their partner, or forcing their partner to have sex with them. The connection between exposure to intimate partner violence and child maladjustment is clear (Ehrensaft et al. 2003), with two meta-analyses showing that children from violent families have elevated rates of internalizing and externalizing symptoms, academic problems, and peer problems (Kitzmann et al. 2003; Wolfe et al. 2003; also see DeBoard-Lucas and Grych 2011). Further, witnessing violence in the family predicts the perpetration of aggression in intimate relationships in adolescence and adulthood (e.g., Ehrensaft, et al. 2003).

\section{Cognitive-Contextual Framework: Children's Appraisals of Intimate Partner Violence}

Why do so many children exposed to intimate partner violence struggle with emotional and behavioral problems and become victims or perpetrators of violence in their own relationships? Although multiple processes undoubtedly are involved, the subjective meaning that children draw from hostile and aggressive interactions in the family is proposed to be a critical factor in shaping its immediate and longterm impact on them (Fosco et al. 2007; Grych 2000; Grych and Fincham 1990). The cognitive-contextual framework (Grych and Fincham 1990; Grych et al. 1992) holds that when children witness aggression between their caregivers, they actively process and try to make sense of what is happening, and that their appraisals have implications for their immediate response in the situation and their long-term functioning. More specifically, it proposes that children appraise the degree of threat the interaction poses to them or their families, why it is occurring, and how they should respond. Appraisals involve emotion as well as cognition (e.g., the appraisal of threat includes both the feeling of fear and the perception of danger), and guide children's efforts to cope.

Interparental aggression can be threatening to children for several reasons, including the fear that a parent will be hurt or killed, or that they will become a victim as well (also see Davies and Cummings 1994). What children view as threatening may influence how they respond (e.g., try to protect a parent vs. the self); and although it is adaptive to accurately perceive threats in the environment, chronically experiencing high levels of threat increases the risk of developing internalizing problems (e.g., Grych et al. 2000). Children's attributions for the cause of a violent interaction also may guide their coping efforts in the situation. For example, children who feel responsible for causing a fight 
may have stronger motivation to intervene or try to stop the interaction, which can place them in physical danger. Children's understanding of why violence occurred also has the potential to inform their expectations about its recurrence and beliefs about its justifiability (Fosco et al. 2007; Thompson 1989). Children exposed to aggression between caregivers may come to believe that aggression can be an acceptable or effective way to respond to conflict and consequently become more willing to use violence themselves (Ehrensaft et al. 2003; Fosco et al. 2007; Jaffe et al. 1990). Finally, expectations regarding their ability to cope effectively in the situation are proposed to influence their behavioral response and more general levels of anxiety and depression.

\section{Children's Exposure to Interparental Aggression, Appraisals, and}

\section{Adjustment}

Cross-sectional and longitudinal research provide empirical support for links between children's exposure to interparental aggression, appraisals, and adjustment (for a recent meta-analysis, see Rhoades 2008). Children who blame themselves for their parents' conflict consistently exhibit more internalizing and externalizing problems (Fosco and Grych 2008; Grych et al. 2003), and those who report higher levels of threat experience more internalizing problems. Further, appraisals appear to function similarly in violent and nonviolent families (e.g., Grych et al. 2000; Jouriles et al. 2000; McDonald and Grych 2006). For example, Grych et al. (2000) found that threat appraisals mediated the association between exposure to interparental conflict and internalizing problems in families recruited from the community and from domestic violence shelters; and self-blame mediated links between conflict and internalizing symptoms in boys in both samples and girls in the shelter sample. Beliefs about the acceptability of aggression also predict youths' behavior. Adolescents' beliefs about the justifiability of interpersonal violence mediate the association between youths' exposure to interparental conflict and their aggression toward peers and dating partners (Grych and Kinsfogel 2010; Kinsfogel and Grych 2004), as well as between parent-child aggression and their aggression toward peers (e.g., Calvete 2007; Dodge et al. 1995; Herrenkohl et al. 2003; Marcus et al. 2001) .

Astor (1994) further explored children's perceptions of the acceptability of aggression by examining how provocation affected their judgments. School-aged children read a series of vignettes in which physical aggression occurred between peers, siblings, a parent and child, and two parents; in half of the cases, the aggression was unprovoked, and in the others it was preceded by a verbal provocation. Participants were then asked to decide whether the physical aggression was justified and to explain their reasoning. Children who were rated by teachers and school personnel as exhibiting high levels of aggression at school were significantly more likely than nonviolent children to approve of interparental violence when the perpetrator was provoked. When asked to provide justification for their judgments, violent children focused on the psychological harm the aggressor felt in connection to being provoked (i.e., through name calling, lying, stealing). In contrast, nonviolent children focused on the physical harm associated with the act of hitting. Further, aggressive children focused on the provocation as immoral, whereas nonviolent children viewed both provocation and retaliation as wrong. These results suggest that if children view one caregiver as provoking the other, they may regard violence as acceptable in the situation.

Research thus indicates that children's perceptions and beliefs about interparental violence are important for shaping the impact of these family interactions; however, with the exception of the Astor 
(1994) study, it has relied on self-report questionnaires or structured interviews that ask children to respond to questions about theoretical constructs viewed as important by the researchers. These types of questions are valuable for testing theory but they do not necessarily reveal how children think about violence on their own (Schwarz 1999). Consequently, we do not know if the appraisal processes described in the cognitive-contextual framework represent the kinds of thoughts that occur spontaneously when children witness interparental aggression.

The goal of this study was to investigate children's perceptions of violent interactions between their caregivers from a phenomenological perspective (see Starks and Trinidad 2007). We developed a semistructured interview that asked children exposed to family violence to describe an aggressive interaction between their caregivers and to report what they thought about, how they felt, and what they did when they witnessed the interaction. These questions reflect the general kinds of intrapersonal processes highlighted in the cognitive-contextual framework (i.e., cognitions, emotions, behavior), but we used open-ended questions that allowed children the freedom to describe their experiences in their own words. We also asked the children why they thought violence occurred in families in order to assess their general beliefs about the causes of interparental violence. Attributions for the cause of an event are central to making meaning out of experiences and often are used to evaluate issues of culpability and justifiability for particular behaviors (Corrigan and Denton 1996; Crick and Dodge 1994; Keil 2006). Interparental violence is likely to be especially difficult for children to understand because it presents a conflict between the cultural prescription that violence is wrong and the behavior of someone to whom they are close. Consequently, learning what children believe about why intimate partner violence occurs is critical for understanding how it may affect them in the short- and long-term. In addition to describing the kinds of thoughts and feelings children report about interparental violence, we examined whether their responses were related to children's age, gender, or relation to the mother's partner.

\section{Method}

\section{Participants}

Participants were recruited from community agencies providing shelter and outpatient services to victims of domestic violence. Staff at the agencies distributed flyers describing the study, and women who were interested provided their name and phone number to the investigators. Women who had been involved in a physically violent relationship in the past three years and who had a child between seven and twelve years of age were eligible to participate. The inclusion criterion for children's age was set at seven years because children below that age are unable to complete most self-report measures and tend to lack the ability to engage in self-monitoring (Ollendick and Hersen $\underline{1993}$ ). Investigators then called the women who met the inclusion criteria to describe the study, and $87 \%$ of the women contacted consented to participate. Those who declined either did not meet inclusion criteria or reported being too busy to participate. All but one mother was receiving outpatient services though the agency; this final mother-child dyad was residing in shelter at the time of participation. Thirty-four mother-child pairs from ethnically diverse backgrounds participated in the study (African American: 41.2\%; Latina: $41.2 \%$; Caucasian: $14.7 \%$; Biracial: $2.9 \%$ ). Annual income ranged from less than $\$ 10,000$ to $\$ 40,000$, with the average in the $\$ 10-15,000$ range. Children's ages ranged from 7 to 12 years ( $M$ : 10.26 years; $S D: 1.71$ ), and approximately equal numbers of boys and girls participated (18 girls). For 15 women, their partners were the biological fathers of the children participating; the remaining partners either were married to the mothers but were not biological fathers to the children $(n=4)$ or were their 
romantic partners $(n=5)$. Eight of the women were living with their partner at the time of participation, and 26 were not.

\section{Procedures}

Children participated in a semi-structured interview that lasted 30-45 minutes. Mothers completed a questionnaire on intimate partner violence in order to characterize the frequency and severity of violence occurring in the homes. The interview and questionnaire were part of a larger study, and participants completed other measures not included in the present report. All but two dyads participated at the agency where they were receiving services; due to travel constraints, two of the mother-child pairs participated at a university research lab. The interviews were conducted by either two graduate students in clinical psychology or one graduate and one advanced undergraduate psychology student. The mothers provided informed consent and the children provided assent to participate. With the mother and child in the same room, the researchers explained that they were mandated reporters of instances of intent to harm the self or others and cases of unreported child abuse. Mothers could choose to complete the questionnaires in English or Spanish, and to fill out the questionnaires on their own or with the assistance of a research assistant. All of the children were fluent English speakers.

\section{Measures}

\section{Perceptions of Intimate Partner Violence Interview}

After a period of rapport-building, children were asked if they had ever seen or heard their mother and her partner fighting, and if so, to describe a fight that they had witnessed. If children described interparental aggression but labeled it with a term other than "fight" we used the child's term as the referent for all subsequent questions. All but two children stated that they had witnessed violent interactions between their caregivers. Interviewers used nondirective probes, such as "and then what happened?" to elicit as detailed a description of the fight as possible. Children then were asked a set of open-ended questions about their thoughts, feelings, and behavioral responses when the fight occurred. The questions were:

"What thoughts went through your head when they fought (or term used by the child)?" "How did you feel when they fought (or term used by the child)?"

"What did you do when they fought (or other term used by child)?"

Nondirective probes again were used in order to clarify or extend children's responses; for example, "Did you think about/feel/do anything else?" Finally, children were asked a more global question, "Why do you think violence happens in families?" in order to elicit their general beliefs about the causes of violence between family members.

Children's responses to the open-ended questions were coded in one of two ways. The questions about the behaviors that parents engaged in during the interaction, children's thoughts, and their behavioral responses were coded using a coding scheme developed for a prior study of interparental conflict. Children's beliefs about why violence occurs in families were coded into categories derived for the present study. Two coders rated the child interviews: one coder rated all of the interviews, and the second coder rated half of the interviews to establish interrater reliability. Disagreements were resolved 
through discussion of the particular code. The codes used to assess each construct are described below, and in Tables $\underline{1}, \underline{2}, \underline{3}$ and $\underline{4}$.

Table 1. Children's narrative reports of parent behaviors during violent interactions

\begin{tabular}{|l|l|l|}
\hline Parent Behavior & Partner (\%) & Mother (\%) \\
\hline Talking & 5.9 & 5.9 \\
\hline Avoidance & 2.9 & 2.9 \\
\hline Withdrawal & 11.8 & 5.9 \\
\hline Parent Cries & 0 & 8.8 \\
\hline Verbal Aggression & 38.2 & 32.4 \\
\hline Contempt & 20.6 & 11.8 \\
\hline Aggression against an Object & 2.9 & 5.9 \\
\hline Physical Aggression & 64.7 & 20.6 \\
\hline Child-directed anger/aggression & 11.8 & 0 \\
\hline
\end{tabular}

Table 2 Children's thoughts about violent interactions

\begin{tabular}{|l|l|}
\hline & (\%) \\
\hline Threat (76.5) & \\
\hline Parent Well-being & 37.5 \\
\hline Uncertain Outcomes & 25.0 \\
\hline Disruption to the Marriage/Partnership & 6.3 \\
\hline Child Well-being & 6.3 \\
\hline Disruption to the Parent-Child Relationship & 3.1 \\
\hline Blame (82\%) & \\
\hline Partner & 56.3 \\
\hline Both Partner \& Mother & 31.3 \\
\hline Child & 3.1 \\
\hline Mother & 0 \\
\hline Thoughts about Intervening & 41.2 \\
\hline Thought about Intervening & \\
\hline
\end{tabular}


Table 3 Behavioral responses during violent interactions

\begin{tabular}{|l|l|}
\hline Behavioral Response & \% \\
\hline Withdraw & 50.0 \\
\hline Observe & 32.4 \\
\hline Direct intervention & 29.4 \\
\hline Seek Support/Companionship & 17.6 \\
\hline Indirect intervention & 14.7 \\
\hline Withdraw to Observe & 11.8 \\
\hline Emote & 8.8 \\
\hline
\end{tabular}

Table 4 Perceived causes of intimate partner violence

\begin{tabular}{|l|l|}
\hline Perceived Cause & $\%$ \\
\hline Perpetrator losing control of anger & 38.0 \\
\hline Victim provoked perpetrator & 35.3 \\
\hline Perpetrator characteristics & 29.4 \\
\hline
\end{tabular}

Parental Behavior During Violent Interactions (Table $\underline{1}$ )

Parental behavior during fights was coded into categories that reflected a variety of nonaggressive and aggressive behavior, ranging from talking to withdrawal to physical aggression directed at their partner, child, or an object. Each category was coded ' 1 ' to indicate that the particular behavior occurred and ' 0 ' to indicate that it did not occur. Interrater reliability for this code was very good $(K=1.0, p<.05)$.

Thoughts About Violent Interactions (Table 2

Most of the statements reflecting children's cognitions during the violent interaction occurred in response to the question, "What thoughts went through your head when your parents fought?" However, thoughts were coded if they occurred at any point in the interview, as were emotions and behavioral responses. Children's statements were categorized into three general classes: concerns about the fight or its consequences (Threat), perceptions of who or what caused the particular fight (Blame), and questions/comments about whether they should get involved in the fight (Thoughts about Intervening). Note that the last code is different from children's description of what they actually did when the fight occurred; children could report thinking about whether they should intervene even if they did not try to stop the fight, and could try to intervene without reporting it as something that they thought about during the interaction. Statements that did not fit into one of these three categories were coded as "Other" and were examined to determine if additional categories were needed to adequately represent children's thoughts.

Threat codes reflected fears or concerns that children expressed regarding the consequences of the aggression, and included worries that they or their parent might be hurt, that the parents would split up, 
or uncertainty about what would happen. The specific categories included in the Threat code are listed in Table 2. Each category was coded ' 1 ' if the child mentioned it, and more than one type of threat could be coded. Interrater reliability on the Threat codes ranged from moderate to very good $(K=.67, p<.01$ to $K=1.0 ; p<.05$ ) (Peat 2001). Blame for the violent interaction was coded if the child made a statement that identified who or what started or was responsible for causing the fight: the partner, mother, child, and/or the situation. Agreement between coders was good ( $K=.78, p<.001)$. Thoughts about Intervening was coded " 1 " if the child reported that $s /$ he thought about getting directly involved in the interaction. Percent agreement for this code was very good $(K=1.0, p<.05)$.

\section{Emotions During Violent Interaction}

This variable was coded by simply recording what emotions children reported feeling during the violent interaction. Responses were categorized as fear/worry, anger, sadness, or distress. Positive emotions also could be coded if they occurred. Interrater agreement was very good for each emotion $(K=1.0, p<.05)$.

\section{Behavioral Responses During Violent Interactions (Table $\underline{3}$ )}

Children's descriptions of what they did when their caregivers fought were coded into several categories: direct intervention, the child interrupts or becomes directly involved in the interaction in an effort to stop it (e.g., distract the parents, try to physically separate them); indirect intervention, the child tries to do something to address the problem without getting directly involved (e.g., call 911, go get someone else to stop the fight); withdraw, the child leaves the room (but may still be able to see or hear the fight - withdraw to observe); seek support/companionship, the child leaves the room to be with a sibling, friend, or other supportive person; emote, child expresses an emotion behaviorally (i.e. crying); observe, child remains in the room and simply watches the fight; and distract self, where the child remains in the room but engages in another activity (e.g., reading a book or watching TV). Interrater agreement for each behavioral response was very good $(K=1.0, p<.05)$.

\section{Perceived Causes of Intimate Partner Violence (Table $\underline{4}$ )}

Children's responses to the question, "Why do you think violence occurs in families?" were sorted into categories that reflected distinct themes. Five interviews were selected at random to identify the initial set of themes. They produced three general categories that were used for the remaining interviews: Perpetrator Anger, Provocation by the Victim, and Characteristics of the Perpetrator. Additional codes could be created if children described other kinds of causes in sufficient number; however, as described below, nearly all of children's responses could be classified into one of the three codes. Interrater agreement for beliefs about why violence occurs in families was very good $(K=.82, p<.001)$.

\section{Revised Conflict Tactics Scale}

The Revised Conflict Tactics Scale (CTS2; Straus et al. 1996), was completed by the mothers to identify the frequency and severity of domestic violence experienced and committed by the women in the past year. The CTS2 contains 78 items that mothers completed using a seven point Likert scale, with higher numbers representing more frequent violence $(0=$ never; $6=$ more than 20 times $)$. Specifically, the psychological aggression (e.g., "Insulted or swore at the other"), physical aggression and violent tactics (e.g., "Pushed or shoved my partner"), and injury (e.g., "Had a sprain, bruise, or small cut because of a fight with my partner) subscales were used in the current study (Straus et al. 1996). Internal reliability for these three subscales was shown to be acceptable in the current study ( $\alpha: .90)$. Preliminary evidence of construct validity has also been found in other studies (Straus et al. $\underline{1996}$ ). 


\section{Results}

\section{Children's Exposure to Intimate Partner Violence}

All but two of the children were able to describe a specific aggressive interaction involving their caregivers. Their descriptions of these fights commonly included verbal and physical aggression, with more children reporting partner-to-mother physical aggression than mother-to-partner physical aggression (see Table 1 ). Children's responses to questions about specific conflict behaviors provide a more detailed look at their exposure to violence and indicate that children witnessed a substantial amount of physical aggression. A majority of the children (70.6\%) reported seeing their mother pushed or shoved by their partner; $35.3 \%$ witnessed their mother's partner kick, bit, or punch their mother with a fist; $23.5 \%$ saw the partner throw an object at their mother; and $14.7 \%$ reported seeing a weapon used against their mother. Several children reported being the object of the partner's anger or aggression but none indicated that their mothers were aggressive towards them during interparental conflicts.

Mothers also reported a substantial amount of violence in their relationships: $58.8 \%$ of the women reported being pushed or shoved by their partner, and $38.2 \%$ said they had done this to their partner; $53 \%$ of the women indicated that their partner threw something at them that could hurt, whereas 44.1\% indicated that they had done this to their partner; $47.1 \%$ reported that 'My partner beat me up' and $26.5 \%$ had beaten up their partner; and $14.7 \%$ of the women reported that 'My partner used a knife or gun on me' while $17.7 \%$ had used a weapon during a fight. Consistent with children's reports, women reported experiencing more acts of verbal and physical aggression than they committed.

\section{Children's Reports of Their Thoughts}

When asked, "What thoughts went through your head when your parents fought?" $76.5 \%$ of the children gave at least one codable response, whereas $23.5 \%$ said "I don't know" or "I can't remember." Of the children who reported a thought, nearly all (94\%) described concerns or fears about what would happen during or following the fight. These responses were coded as perceptions of Threat (see Table 2 ) and fell into four subcategories. The most common Threat response expressed a fear that one or both parents would be hurt (37.5\%). One child, for example, said she worried about her mother's boyfriend "breaking through the window, and the knife...I thought he was really gonna do it" (i.e., kill her mother). The second most common response reflected uncertainty about what was going to happen (25.0\%). For example, children made statements such as "Why won't they stop fighting?" or "Is mom going to call someone?" (i.e., for help). A small percentage of children (6.3\%) feared for their own well-being, either during or after the fight. For example, one child said “We have to move out because we didn't really have a place to go." Dissolution of the parental relationship also was a concern for some children (6.3\%), one of whom said tearfully "I knew they weren't going to be together for a long time." One child reported fears about disruption to the parent-child relationship. Three children reported other types of concerns, but they were not similar enough to form a new code.

Most children (82\%) also spontaneously made statements regarding the responsibility or blame for the fight. These were coded as attributions of Blame and nearly all could be classified into one of two categories: $56.3 \%$ perceived their mother's partner as solely responsible for the conflicts and $31.3 \%$ saw both the mother and her partner as responsible. In addition to naming both parents as responsible for the fight, one child added that he also was partially to blame. No children stated that their mothers were solely to blame for the fight. 
Finally, children's comments regarding whether they should become involved in the interaction were coded as Thoughts about Intervening. This code is distinct from the codes representing what children stated that they actually did, which are described below in the Behavioral Response section. More than a third of children (41.2\%) reported that they thought they should do something to try to stop the fight, either verbally or physically. One child described a desire to strike back at his father, saying that his thoughts during the fight were "Kill my dad...not kill, push him."

\section{Children's Reports of Their Emotions}

Children were asked "How did you feel when your parents fought?" to assess the emotions they experienced when they witnessed their parents fighting. Only three emotions were reported, and $34 \%$ of children reported more than one emotion in response to this question. The most frequently reported emotions were sadness $(50.0 \%)$ and anger $(47.1 \%)$, with a small percentage indicating that they felt scared during the fight (14.7\%).

\section{Children's Reports of Their Behavioral Responses}

Children described a range of behaviors when asked "What did you do when your parents fought?" Most reported engaging in more than one behavior during the fight, and thus responses exceed $100 \%$. The most frequently reported behavioral response was to leave the room where the interaction took place (50.0\%). Approximately one third of children (32.4\%) reported that they stayed in the room and watched the interaction, with an additional $11.8 \%$ indicating that they left the room but continued to watch or listen to the interaction (11.8\%). Almost one-third of the children (29.4\%) stated that they intervened in the violence in some way. Direct Intervention includes efforts to interrupt or distract their caregivers as well as attempts to physically separate their parents while fighting. About half as many children (14.7\%) described doing something to try to stop the fight without getting directly involved, such as calling the police or getting a family member to help. A similar percentage (17.6\%) reported that they sought support from a family member or friend when violence was happening between their parents. A smaller number of children reported crying or expressing another emotion during violent interactions (8.8\%).

\section{Perceived Causes of Intimate Partner Violence}

After discussing a specific incident of violence that they had witnessed, children were asked a more general question about why they thought that violence occurred in families. Most of the responses could be coded into one of three categories. The most frequently identified reason was the perpetrator losing control of his/her anger (38\%). For example, one child who endorsed this theme said "They (the perpetrator) were mad about some situation." Almost as many children (35.3\%) stated that violence occurs because the victim provoked the perpetrator in some way. Provocation often involved saying or doing something to upset the perpetrator. Children whose responses fell into this category made statements such as "...cause some people, they say stupid stuff, and, and, the next person get mad and they just start fighting," and "Maybe cause they (victims) were being mean to them (perpetrators) one time. So they got a payback." Some children also stated that violence could occur because the victim did not comply with the perpetrator. For example, "They (victims) don't do what they (perpetrators) want them to do." The third most common reason (29.4\%) for violence related to characteristics of the perpetrator. Sample responses in this category included, "because they're mean," "probably they're jealous," and "maybe because they're not happy with themselves." These explanations generally reflected qualities of the perpetrator that seemed to be unchangeable or beyond the perpetrator's 
control. The responses of five children did not fit into one of the three categories. However, there were not a sufficient number of conceptually similar responses among the five to create any additional categories: one child identified alcohol use as the cause of the violence, one stated that children cause family violence, and two referred to family secrets or gossip as the cause. One child did not provide sufficient information to code their perceived cause of violence.

\section{Gender, Age, and Relation to the Male Partner}

In addition to describing the kinds of thoughts and feelings children report about interparental violence, we used chi square tests to examine whether children's responses were related to their gender, age (classified as 7-10 years or 10-12 years), or relation to the male perpetrator of violence (coded as biological father or not). Only three significant differences were found. First, girls were more likely than boys to report being scared during their parents' violent interactions $\left(X^{2}(1)=4.61, p<.05\right)$. An odds ratio could not be calculated because none of the boys stated that they were scared during the fight, making the denominator of the equation zero. Second, there was a marginally significant effect of children's relation to the male partner on children's fear during interparental fights $\left(X^{2}(1)=3.16, p=.08\right)$. Children were 6.78 times more likely to be scared when the partner was their biological father versus when the partner was not related to the child. Third, there was a marginally significant age effect on perceived threat to parents' safety $\left(\mathrm{X}^{2}(1)=3.21, p=.07\right)$. Older children were 4.17 times more likely than younger children to worry about a parent's well-being during fights. No other significant differences were found based on gender, age, or relation to the male partner.

\section{Discussion}

The goal of this study was to better understand children's perspectives of intimate partner violence by asking them to describe their perceptions and reactions to aggressive interactions that they had witnessed between their caregivers. The sample was recruited from agencies serving battered women, and these pre-adolescents were exposed to high levels of verbal and physical aggression between their caregivers. Most could describe their thoughts, feelings, and behaviors when asked open-ended questions about them, and their spontaneous reports overlapped considerably with intrapersonal processes hypothesized to occur when children observe interparental conflict and aggression (Grych and Fincham 1990). With three exceptions, children's responses were not related to their age, gender, or relation to their mother's partner.

This study shows that pre-adolescents can report reliably on their experiences with violence in the home, and these reports offer valuable insights into children's efforts to understand violent interactions.

\section{Children's Thoughts About Interparental Violence}

After describing a fight that they had witnessed between their parents or caregivers, children were asked what they were thinking during the interaction. Over three-fourths of the children gave codable responses, and of those, nearly all reported worries or fears about what might happen. The most common fear reflected a concern that their mother would be injured or even killed, followed by comments that reflected uncertainty about what was going to happen, such as wondering when or how the fight would end. These spontaneous reports are consistent with the proposition that appraisals of threat are highly salient to children who witness interparental violence and underscore how distressing such interactions can be (Fosco et al. 2007; Grych and Fincham 1990). A marginally significant finding indicated that older children are more likely to worry about their parent's well-being when violence 
occurs, suggesting that children older than age 10 are more attuned to the potential for injury or negative consequences and/or have witnessed more episodes of violence resulting in injury compared to younger children.

Few children expressed worries about their own safety, which is somewhat surprising given that child abuse is fairly common in families in which intimate partner violence occurs. It may be that when interparental violence occurs the threat to their parent is much more salient than the potential for aggression to be directed toward them. Indeed, a number of children reported trying to intervene in these fights, thus potentially putting themselves in harm's way. Statements about the future of the parents' relationship also occurred but were rare; and it is not clear whether comments about whether the parents would stay together reflected a concern or a hope. This may be an important difference between violent and nonviolent families. For most children living in nonviolent families, the possibility that their parents or caregivers may split up is very distressing and threatens their desire for a secure and stable family (Davies and Cummings 1994; Grych and Fincham 1999). In contrast, some children living in violent families may wish for the relationship to end in the hope that the violence ends as well, especially if they do not have a close relationship with their mother's partner.

The second most common type of thought, reported by over $80 \%$ of the children, pertained to the responsibility for the fight or who was to blame for it. Most of the children (56.3\%) who reported an attribution perceived their mother's partner as solely responsible for causing the fight, with about half as many (31.3\%) indicating that both the mother and her partner were responsible. In the latter case, the fight typically was attributed to both parents behaving aggressively ("My mom hit him and he hit her back") or contributing to the fight ("He'd start nagging at my momma and my momma throw something at him and then they start fighting"). None of the children described their mother as solely to blame for the fight, and only one child felt that he himself was partially to blame for the conflict (he also viewed his parents as responsible). Empirical evidence indicates that children in intact families do not blame themselves for parental conflict as much as is commonly thought, and that self-blame occurs primarily when the topic of the conflict is related to the child (e.g., Grych and Cardoza-Fernandes 2001; Grych and Fincham 1993). Self-blame appears to be even rarer in response to intimate partner violence, perhaps because children do not tend to believe that something that they did could lead to one parent hurting the other. However, it also is possible that the children in this study, whose mothers were receiving services from agencies serving battered women, had worked with counselors or other staff who mitigated any propensity to blame themselves for the violence.

Although self-blame for causing interparental violence was nearly nonexistent in this sample, many children felt responsible for stopping the violence. Almost half of the children reported thinking that they should intervene in the fight, and approximately the same number stated that they had tried to stop it either directly (e.g., by attempting to physically separate parents) or by getting help from others (e.g., calling 911). Prior research on parental conflict generally has not distinguished between these two types of responsibility, but the distinction is critical for applied as well as conceptual reasons. Clinicians working with children exposed to ongoing violence are likely to be more helpful if they focus on fostering children's ability to cope effectively with violence and on the safety concerns elicited by intervening in the interaction, rather than addressing the possibility that children blame themselves for the violence. 
Nearly one-quarter of the children indicated that they did not know or could not remember what they thought about during the violent interaction that they described. These responses could reflect a number of factors, including the possibility that they were overwhelmed by affect at the time and did not form clear thoughts or that they simply could not recall what they thought. For some children the violence occurred many months earlier, and it is plausible that their memory for the content of their thought processes had faded. It also is possible that some children were reluctant to share their thoughts about an event that was very upsetting to them. Future research would benefit from assessing children's perceptions soon after the occurrence of domestic violence in order to better distinguish the effects of time on memory from difficulties with forming or expressing their thoughts.

\section{Children's Emotions During Intimate Partner Violence}

Children also were asked to describe the emotions they experienced when their parents fought, and most said that they felt sad $(50 \%)$ or angry $(47.1 \%)$, with a minority $(14.7 \%)$ indicating that they felt scared. Approximately one-third reported more than one emotion, suggesting that children's emotional responses to violence often are complex. Stein and Levine (1989) hold that emotions arise in response to individuals' evaluations of how events affect important goals that they hold - what is "at stake" in the situation. They propose that anger is elicited when individuals perceive that an important goal is threatened, but there is a possibility that the goal can be maintained or reinstated, or when they perceive that a moral principle has been violated. In each case, anger also motivates the individual to try to preserve the goal or stop the moral violation (Saarni et al. 1998; Stein and Levine 1989; Stein and Liwag 1997). What is "at stake" when interparental violence occurs-the health and safety of their caregiver-is of fundamental importance to children and it appears that many children believe that they could stop the threat if they intervene. Further, most children view violence as wrong in principle (e.g., Astor 1994), which also may evoke anger in this context.

Sadness also can be elicited by a threat to an important goal, but in contrast to anger, occurs if reinstatement of the goal is viewed as unlikely (Stein and Levine 1989). Children's reports of sadness may be indicative of the long-standing nature of the discord and aggression between caregivers: if parents have been fighting for periods of months or years, children may be resigned to the idea that violence is not likely to end and/or view themselves as unable to stop it. Sadness and resignation may in turn lead to withdrawal rather than intervention as a coping response. It is surprising that more children did not report fear, especially when the threat posed by conflict was so salient, but it is possible that children were reluctant to acknowledge feeling afraid in front of an interviewer. This may have been especially true for boys, none of whom reported feeling fearful or worried (see Crockenberg and Langrock 2001) for similar findings).

\section{Children's Behavioral Responses to Intimate Partner Violence}

As noted above, children often described engaging in multiple coping responses when they witnessed violence. The most frequent behavior, reported by half of the children, was to withdraw from the interaction, though some continued to watch or listen at a distance. Nearly one third of the children indicated that they tried to stop the fight by intervening directly, which included physically separating their parents during fights and telling them to stop fighting, and several children tried to stop the fight without directly intervening, such as by calling the police or getting a family member to stop the violence. These findings are consistent with research on interparental conflict showing that intervention and withdrawal are primary ways that children respond to the threat posed by parental discord (e.g., 
Davies and Cummings 1994), and also reflect the distinction between problem-focused and emotionfocused coping (Kerig 2001). When faced with a distressing event, children (and adults) typically either try to stop or alter the stressor (e.g., problem-focused coping) or they attempt to modulate their affect without changing the situation (e.g., emotion-focused coping), perhaps by removing themselves from the source of the stress (Kerig 2001).

Given the risk to their personal safety, it is alarming that so many children reported attempting to intervene in the fight, but their doing so reflects how threatening intimate partner violence is to children. Children exposed to such violence are faced with a difficult dilemma: trying to stop the fight could prevent their caregiver from being hurt, but at the same time it exposes them to danger. Their perceptions of threat suggest that the danger to themselves is not as salient as the danger to their parent, and consequently may not be a barrier to intervention for many children. The situation may be different for children who frequently have experienced physical abuse, who may be more likely to anticipate that they could be victims of violence as well if they tried to stop a fight between their caregivers. Interventions with children may help children find ways to stop violence without putting themselves directly in danger, for example, by encouraging them to seek out an adult to intervene or calling the police (Peled 1998).

\section{Perceived Causes of Intimate Partner Violence}

Finally, children were asked a more general question about why they thought violence occurs in families. Their responses reflected three primary themes. Children most frequently attributed domestic violence to a perpetrator losing control of his or her anger, with provocation by the other caregiver and stable characteristics of the perpetrator mentioned nearly as often. The explanations that children derive from interparental aggression are important because of their potential influence on their broader beliefs about if and when violence is acceptable in close relationships. Children are taught from early on not to hurt others and, in general, view violence as wrong (see Astor 1994); however, children and adults admit exceptions to this moral principle, or conditions under which aggressive behavior is legitimate or justifiable. The present findings suggest that provocation by the victim of violence presents one such condition. The boundaries of what constitutes sufficient justification are indistinct. However, Astor (1994) found that aggressive children viewed one parent's aggression against another as acceptable if it was provoked by name-calling, lying, or stealing. If children perceive intimate partner violence as an appropriate response to being 'wronged' in some way, they may also be less likely to have empathy for the victim and to respond to perceived provocation with aggression in their own relationships. Similarly, although children who attributed family violence to perpetrators losing control over their anger are not necessarily condoning the violence, to the extent that they see it as excusing the behavior, they may be more likely to engage in or accept violent relationships as teens or adults (Ehrensaft et al. 2003).

The third theme related to perpetrator characteristics that are internal and perhaps stable qualities. For example, some children stated that people act aggressively because they are mean, jealous, or not happy with themselves. These responses suggest that the perpetrator cannot change his or her qualities or behavior and thus, that violence will continue to occur (Thompson 1989). However, this type of causal perception may bode better for children's attitudes about the acceptability of intimate partner violence if children who see violence as due to a perpetrator's own negative internal characteristics do not perceive themselves as possessing those qualities. A lack of identification with individuals who use violent behavior may lead these children to look less favorably on violent behavior and to be less likely to emulate it later in life. Alternatively, it is possible that if children perceive violent 'tendencies' as 
unchangeable, they may accept them as part of their partner's personality and not expect them to try to change their behavior.

\section{Clinical Implications}

In addition to informing theory on the effects of family violence on children, understanding children's subjective experiences of violence in the family has implications for the development of effective strategies to prevent violence and to intervene in violent families. Although cognitive behavioral interventions have been used effectively with children exposed to domestic violence (Cohen et al. 2004; Graham-Bermann 2001; for a review, see Vickerman and Margolin 2007), none have focused specifically on children's efforts to explain why violence occurred in their family. McGee (2000) found that children wanted to talk about their experiences with domestic violence, but said that they needed a safe place to talk and assistance in describing what they had witnessed. Individual or group interventions can provide such an opportunity, and could help children make sense of and cope with violence in their families. It is reassuring that children did not blame either themselves or their mothers (at least not exclusively) for the violent interaction they witnessed, but the finding that a substantial minority focused on provocation by the victim as the cause of family violence suggests that this is an important issue to address in the context of therapy or psychoeducational groups. Including attention to children's beliefs about the responsibility for and justifiability of aggressing against an intimate partner may reduce the likelihood that they will perpetrate aggression in their own close relationships later in life. Similarly, identifying the specific thoughts and feelings that children have when violence occurs can help to identify coping responses that will help to regulate their affect without putting themselves in danger.

\section{Limitations and Conclusion}

Despite the insights into children's subjective responses to violence that this study provides, there are limitations that should be acknowledged. The small sample is problematic because it limits power and variability. Although it would be interesting to test associations among children's thoughts, feelings, and behavior, the sample size was inadequate to do so. Even the simple comparisons involving age, gender, and children's relationship to the male caregiver were low in power; therefore the lack of significant differences should be viewed as tentative until larger-scale investigations can be conducted. Another methodological limitation is variability in the amount of time that had passed since domestic violence last occurred in the women's relationships. Children may have different perceptions of what caused violence if it is currently happening versus if it has not happened in several months. In addition, children's recall of their thoughts, feelings, and responses at the moment violence was occurring may have changed over time.

In summary, this study supports the value of assessing children's experiences of family violence from their own perspective. This approach is a useful complement to questionnaires designed to test specific theoretical constructs, and the overlap between the thoughts, feelings, and behavior freely reported by the children in this sample and the processes outlined in the cognitive-contextual framework (Grych and Fincham 1990; Grych et al. 1992) offers further evidence for its validity and applicability to violent families. Further, it suggests that children's efforts to understand violence that they witness in the home may be instrumental in the development of beliefs and attitudes that predict the perpetration of aggression in close relationships. Further research with larger and more diverse samples is likely to offer insight into a potentially important mechanism for understanding links between experiences in the family and behavior with romantic partners in adolescence and adulthood. 


\section{References}

Astor, R. A. (1994). Children's moral reasoning about family and peer violence: the role of provocation and retribution. Child Development, 65, 1054-1067.

Calvete, E. (2007). Justification of violence beliefs and social problem-solving as mediators between maltreatment and behavior problems in adolescents. The Spanish Journal of Psychology, 10, 131-140.

Cohen, J. A., Deblinger, E., Mannarino, A. P., \& Steer, R. A. (2004). A multisite, randomized controlled trial for children with sexual abuse-related PTSD symptoms. Journal of the American Academy of Child and Adolescent Psychiatry, 43, 393-402.

Corrigan, R., \& Denton, P. (1996). Causal understanding as a developmental primitive. Developmental Review, 16, 162-202.

Crick, N. R., \& Dodge, K. A. (1994). A review and reformulation of social information-processing mechanisms in children's social adjustment. Psychological Bulletin, 115, 74-101.

Crockenberg, S., \& Langrock, A. (2001). The role of specific emotions in children's responses to interparental conflict: a test of the model. Journal of Family Psychology, 15, 163-182.

Davies, P. T., \& Cummings, E. M. (1994). Marital conflict and child adjustment: an emotional security hypothesis. Psychological Bulletin, 116, 387-411.

DeBoard-Lucas, R. L., \& Grych, J. H. (2011). The effects of intimate partner violence on school-aged children. In S. A. Graham-Bermann \& A. A. Levendosky (Eds.), How intimate partner violence affects children: Developmental research, case studies, and evidence-based intervention (pp. 155-177). Washington, DC: American Psychological Association.

Dodge, K. A., Pettit, G. S., Bates, J. E., \& Valente, E. (1995). Social information-processing patterns partially mediate the effect of early physical abuse on later conduct problems. Journal of Abnormal Psychology, 104, 632-643.

Ehrensaft, M. K., Cohen, P., Brown, J., Smailes, E., Chen, H., \& Johnson, J. G. (2003). Intergenerational transmission of partner violence: a 20-year prospective study. Journal of Consulting and Clinical Psychology, 71, 741-753.

Fosco, G. M., DeBoard, R. L., \& Grych, J. H. (2007). Making sense of family violence: implications of children's appraisals of interparental aggression for their short- and long-term functioning. European Psychologist, 12, 6-16.

Fosco, G. M., \& Grych, J. H. (2008). Emotional, cognitive, and family systems mediators of children's adjustment to interparental conflict. Journal of Family Psychology, 22, 843-854.

Graham-Bermann, S. A. (2001). Designing intervention evaluations for children exposed to domestic violence: Applications of research and theory. In S. A. Graham-Bermann \& J. L. Edleson (Eds.), Domestic violence in the lives of children (pp. 237-267). Washington, DC: American Psychological Association.

Grych, J. H. (2000). Children's perceptions of family violence: Implications for research and practice. In J. Vincent \& E. Jouriles (Eds.), Domestic violence: Guidelines for research-informed practice (pp. 102-125). London: Jessica Kingsley Publishers.

Grych, J. H., \& Cardoza-Fernandes, S. (2001). Understanding the impact of interparental conflict on children: The role of social cognitive processes. In J. H. Grych \& F. D. Fincham (Eds.), Interparental conflict and child development: Theory, research, and applications(pp. 157187). New York: Cambridge University Press. 
Grych, J. H., \& Fincham, F. D. (1990). Marital conflict and children's adjustment: a cognitive-contextual framework. Psychological Bulletin, 108, 267-290.

Grych, J. H., \& Fincham, F. D. (1993). Children's appraisals of marital conflict: initial investigations of the cognitive-contextual framework. Child Development, 64, 215-230.

Grych, J. H., \& Fincham, F. D. (1999). Children of single parents and divorce. In W. K. Silverman \& T. H. Ollendick (Eds.), Developmental issues in the clinical treatment of children (pp. 321-341). Needham Heights: Allyn \& Bacon.

Grych, J. H., Fincham, F. D., Jouriles, E. N., \& McDonald, R. (2000). Interparental conflict and child adjustment: testing the meditational role of appraisals in the cognitive-contextual framework. Child Development, 71, 1648-1661.

Grych, J. H., Harold, G. T., \& Miles, C. J. (2003). A prospective investigation of appraisals as mediators of the link between interparental conflict and child adjustment. Child Development, 74, 11761193.

Grych, J.H., \& Kinsfogel, K.M. (2010). Exploring the role of attachment style in the relation between family aggression and abuse in adolescent dating relationships. Journal of Aggression, Maltreatment, and Trauma, 19, 624-640.

Grych, J. H., Seid, M., \& Fincham, F. D. (1992). Assessing marital conflict from the child's perspective: the children's perceptions of interparental conflict scale. Child Development, 63, 558-572.

Herrenkohl, T. I., Huang, B., Tajima, E. A., \& Whitney, S. D. (2003). Examining the link between child abuse and youth violence: an analysis of mediating mechanisms. Journal of Interpersonal Violence, 18, 1189-1208.

Jaffe, P., Hurley, D., \& Wolfe, D. A. (1990). Children's observations of violence: I. Critical issues in child development and intervention planning. Canadian Journal of Psychiatry, 35, 466-470.

Jouriles, E. N., Spiller, L. C., Stephens, N., McDonald, R., \& Swank, P. (2000). Variability in adjustment of children of battered women: the role of child appraisals of interparent conflict. Cognitive Therapy and Research, 24, 233-249.

Keil, F. C. (2006). Explanation and understanding. Annual Review of Psychology, 57, 227-254.

Kerig, P. K. (2001). Children's coping with interparental conflict. In J. H. Grych \& F. D. Fincham (Eds.), Interparental conflict and child development: Theory, research, and applications (pp. 213245). New York: Cambridge University.

Kinsfogel, K. M., \& Grych, J. H. (2004). Interparental conflict and adolescent dating relationships: integrating cognitive, emotional, and peer influences. Journal of Family Psychology, 18, 505515.

Kitzmann, K. M., Gaylord, N. K., Holt, A. R., \& Kenny, E. D. (2003). Child witnesses to domestic violence: a meta-analytic review. Journal of Consulting and Clinical Psychology, 71, 339-352.

Marcus, N. E., Lindahl, K. M., \& Malik, N. M. (2001). Interparental conflict, children's social cognitions, and child aggression: a test of a meditational model. Journal of Family Psychology, 15, 315-333.

McDonald, R., \& Grych, J. H. (2006). Young children's appraisals of interparental conflict: measurement and links with adjustment problems. Journal of Family Psychology, 20, 88-99.

McDonald, R., Jouriles, E. N., Ramisetty-Mikler, S., Caetano, R., \& Green, C. E. (2006). Estimating the number of American children living in partner-violent families. Journal of Family Psychology, 20, 137-142.

McGee, C. (2000). Childhood experiences of domestic violence. London: Jessica Kingsley Publishers. 
Ollendick, T. H., \& Hersen, M. (1993). Child and adolescent behavioral assessment. In T. H. Ollendick \& M. Hersen (Eds.), Handbook of child and adolescent assessment (pp. 3-14). Needham Heights: Allyn \& Bacon.

Peat, J. (2001). Health science research: A handbook of quantitative methods. Sydney: Allen \& Unwin. Peled, E. (1998). The experience of living with violence for preadolescent children of battered women. Youth \& Society, 29, 395-430.

Rhoades, K. A. (2008). Children's responses to interparental conflict: a meta-analysis of their associations with child adjustment. Child Development, 79, 1942-1956.

Saarni, C., Mumme, D. L., \& Campos, J. J. (1998). Emotional development: Action, communication, and understanding. In W. Damon \& N. Eisenberg (Eds.), Handbook of child psychology: Social, emotional, and personality development (Vol. 3) (5th ed., pp. 237-309). Hoboken: Wiley.

Schwarz, N. (1999). Self-reports: how the questions shape the answers. The American Psychologist, 56, 93-105.

Starks, H., \& Trinidad, S. B. (2007). Choose your method: a comparison of phenomenology, discourse analysis, and grounded theory. Qualitative Health Research, 17, 1372-1380.

Stein, N. L., \& Levine, L. J. (1989). The causal organisation of emotional knowledge: a developmental study. Cognition and Emotion, 3, 343-378.

Stein, N. L., \& Liwag, M. D. (1997). Children's understanding, evaluation, and memory for emotional events. In P. W. van den Broek, P. J. Bauer, \& T. Bourg (Eds.), Developmental spans in event comprehension and representation: Bridging fictional and actual events(pp. 199-235). Hillsdale: Lawrence Erlbaum Associates.

Straus, M. A., Hamby, S. L., Boney-McCoy, S., \& Sugarman, D. B. (1996). The revised conflict tactics scale (CTS2): development and preliminary psychometric data. Journal of Family Issues, 17, 283-316.

Thompson, R. A. (1989). Causal attributions and children's emotional understanding. In C. Saarni \& P. L. Harris (Eds.), Children's understanding of emotion (pp. 117-150). Cambridge University Press.

Vickerman, K. A., \& Margolin, G. (2007). Posttraumatic stress in children and adolescents exposed to family violence: II. Treatment. Professional Psychology Research \& Practice, 38, 620-628.

Wolfe, D. A., Crooks, C. V., Lee, V., Mclntyre-Smith, A., \& Jaffe, P. G. (2003). The effects of children's exposure to domestic violence: a meta-analysis and critique. Clinical Child and Family Psychology Review, 6, 171-187. 